\title{
Evaluation of AllergiSense Smartphone Tools for Adrenaline Injection Training
}

\author{
L. U. Hernandez-Munoz, Graduate Student Member, IEEE, S. I. Woolley, Senior Member, IEEE, \\ D. Luyt, G. Stiefel, K. Kirk, N. Makwana, C. Melchior, T. C. Dawson, G. Wong, T. Collins and \\ L. Diwakar
}

\begin{abstract}
Anaphylaxis is an increasingly prevalent lifethreatening allergic condition that requires people with anaphylaxis and their caregivers to be trained in the avoidance of allergen triggers and in the administration of adrenaline autoinjectors. The prompt and correct administration of autoinjectors in the event of an anaphylactic reaction is a significant challenge in the management of anaphylaxis. Unfortunately, many people do not know how to use auto-injectors and either fail to use them or fail to use them correctly. This is due in part to deficiencies in training and also to the lack of a system encouraging continuous practice with feedback. Assistive smartphone healthcare technologies have demonstrated potential to support the management of chronic conditions such as diabetes and cardiovascular disease, but there have been deficiencies in their evaluation and there has been a lack of application to anaphylaxis. This paper describes AllergiSense, a smartphone app and sensing system for anaphylaxis management, and presents the results of a randomized, controlled, pre-post evaluation of AllergiSense injection training and feedback tools with healthy participants. Participants whose training was supplemented with AllergiSense injection feedback achieved significantly better practiced injections with $90.5 \%$ performing correct injections compared to only $28.6 \%$ in the paper-only control group. In addition, the results provide insights into possible self-efficacy failings in traditional training and the benefits of embedding self-efficacy theory into the technology design process.
\end{abstract}

Index Terms--Assistive Technology, Pervasive Healthcare, Anaphylaxis Management, Smartphone Wireless Sensing, SelfEfficacy, Self-Management.

\section{INTRODUCTION}

A NAPHYLAXIS is a serious allergic reaction that is rapid in onset and can cause death [1, p. 392]. Its prevalence has dramatically increased in recent years [2] with an

This paper was submitted for review on June $11^{\text {th }} 2015$. This research was supported by the University of Birmingham UK, the Mexican Council of Science and Technology (Conacyt) and the Mexican Secretariat of Public Education (SEP). This study was funded by The Anaphylaxis Campaign UK's Small Grant Scheme (04-13-LHM) and approved by the University of Birmingham Ethics Committee (ERN_13-1496).

L. U. Hernandez-Munoz is with Birmingham City University at Millennium Point, Curzon Street, Birmingham, B4 7XG. (Correspondence e-mail: Luis.Hernandez-Munoz@bcu.ac.uk).

S. I. Woolley, T. Collins and L. Diwakar are with The University of Birmingham. D. Luyt, G. Stiefel and K. Kirk are with the University Hospitals of Leicester NHS Trust. N. Makwana is with Sandwell and West Birmingham Hospitals NHS Trust. C. Melchior is with Heart of England NHS Foundation Trust, T. C. Dawson is with the Worcestershire Acute Hospitals NHS Trust and G. Wong and L. Diwakar are with the University Hospitals Birmingham NHS Foundation Trust. estimated lifetime prevalence of $0.05-2 \%$ [3]-[5]. Anaphylactic reactions can occur rapidly after ingestion, inhalation or contact with an allergen that may be a food, prescription drug, insect sting, or a substance such as latex [6]. Foods are the most common allergens for children, adolescents and young adults while non-food allergens are more common for older adults [7]. Children frequently develop tolerance to milk, egg, soy and wheat allergens by school age, however, allergies to nuts and shellfish are more likely to be lifelong [8].

The first-line treatment for an anaphylactic reaction is the immediate administration of adrenaline (epinephrine) given via a pre-loaded Adrenaline Auto-Injector (AAI) into the outer thigh and an ambulance must be called [9]. If symptoms do not improve in 5-10 minutes a second injection is advised [10], [11]. Correct use of the most commonly prescribed AAI brands, EpiPen ${ }^{\circledR}$ and Jext ${ }^{\circledR}$, requires the correct completion of four steps: 1) safety cap removal, 2) delivery to the thigh, 3) holding in place for 10 seconds and 4) massaging the injection site for 10 seconds. Empty needleless AAI trainer devices are available for the purpose of practicing injections.

The management of anaphylaxis requires allergen avoidance and emergency preparedness [7], [9], [12], [13]. Allergen avoidance includes the inspection of food ingredient labeling [12], [14], for example, a chocolate bar may have precautionary advisory labeling such as "may contain nuts"; and awareness of contamination risks, for example, if food is cut with a knife that has been in contact with an allergen. Emergency preparedness includes knowing how to recognize anaphylaxis symptoms, training in the use of AAIs [15] and having an emergency allergy action plan [9], [10], [16], [17].

The contribution of this paper is three-fold: i) it presents AllergiSense, a prototype smartphone app and sensing system for emergency preparedness in anaphylaxis management; ii) provides laboratory evidence, for an injection feedback tool, of significantly improved practice injection skills; and iii) provides proof-of-concept evidence to support a case for future clinical trials implementing the technology with both physicians and patients inside and outside the clinic.

AllergiSense design and evaluation was motivated by the fact that the correct use of AAIs is significant in anaphylaxis management [18] and because there are widely reported failures in the provision of appropriate training and failures in AAI injection procedure [19]-[29]. For example, Brown et al. 
[20] reported that only 15 out of 100 mothers could correctly demonstrate AAI use despite a prior demonstration. Arkwright and Farragher [30] found that 69\% of the parents of food allergic children attending a UK clinic were unable to use their AAIs, did not have them available or did not know when to administer them. In a randomized study with 343 previouslytrained Canadian school staff, Nguyen-Luu et al. [27] found that only $26.3 \%$ of the participants who had been fully informed at recruitment about the AAI assessment could demonstrate correct AAI use. And only $15.8 \%$ of the participants who were not fully informed about the assessment could correctly demonstrate AAI use. Physicians have also been shown to lack AAI skills [18], [29]. For example, Mehr et al. [31] have suggested that insufficient knowledge from prescribing physicians was a contributing factor to the failure of parents and children activating the device correctly. The authors recruited 100 pediatric hospital physicians (including residents, registrars and consultants), half of whom had already prescribed AAIs. Only $2 \%$ of their demonstrated injections were assessed as fully correct, improving to $41 \%$ after they reviewed AAI instructions but still one in five selfinjected their own thumbs. Similarly, Arga et al. [18] found in a study with 151 general pediatrics physicians, residents and consultants that only thirty-five (23\%) were able to demonstrate correct AAI use, improving to $74 \%$ after training and practice. Observing deficiencies on retesting six months later, the authors [18] recommended repetition of education.

The consensus in the clinical literature is that training should be improved and should ensure correct injection techniques are used, and that training should be continuous, monitored and assessed by allergy specialists so that skills are refreshed and maintained [9], [19], [25], [26], [28], [32], [33].

Advances in pervasive and assistive health technology research, evident in the expanding literature, have contributed toward improved management of other chronic health conditions such as diabetes, asthma, cardiovascular diseases [34]-[36] and mental illness [37], but anaphylaxis has been neglected [38]. A search of online app stores (Android and Apple - August 2014) returned nine information-giving smartphone anaphylaxis apps and services, most of which were produced by support groups [39] and AAI manufacturers [40], [41]. For example, there were apps with instructions for using a manufacturer's AAI, apps providing text reminder services about AAI expiry dates or apps providing text alerts about allergen contamination in the food supply chain. As with other healthcare apps, there is lack of reported evaluation in the literature [42], [43]. In addition, there are no systems or apps providing feedback on injection performance or encouraging maintenance of AAI skills.

We aimed to investigate whether adrenaline injection training using AllergiSense to supplement traditional paper documents, may provide improved injection training skills and better self-efficacy levels in comparison with adrenaline injection training using paper documents alone. The following section presents the design of AllergiSense and then section III describes its implementation. Section IV explains how
AllergiSense injection feedback tools were evaluated and section $\mathrm{V}$ presents the results of the evaluation. Finally section VI provides a discussion of results and section VII outlines the conclusions of this paper.

\section{ALLERGISENSE DESIGN}

\section{A. Design based on self-efficacy theory}

The AllergiSense design and its evaluation were grounded in self-efficacy theory [44]. Self-efficacy theory is central to social cognitive theory. It refers to one's belief in one's ability and it is a major predictor of self-management outcomes and a contributor to performance ibid.

Self-efficacy is modified by four information sources [44]: Enactive experience - experiencing attainment through practice and mastery. Vicarious experience - modeling others. Social persuasion - encouragement or discouragement from others. Physiological states - interpretation of one's physiological responses as indicators of personal competency.

Health-promotion interventions based on social and behavioral science theories are more effective than those without a theoretical base [45]. Though technology evaluations may incorporate assessments of self-efficacy, the majority of reported studies are not theoretically based on such. In a review of mobile devices for healthcare and behavioral change, Free et al. [35] observed only seven of twenty-six (26.9\%) behavioral change studies reported using behavioral change theories to underpin their intervention.

\section{B. Design methodology}

The ambition of AllergiSense was to support anaphylaxis self-management. The design and evaluation was informed by technological prototyping [38], [46], participatory design [47] and a multi-stage methodology enriched with embedded self-

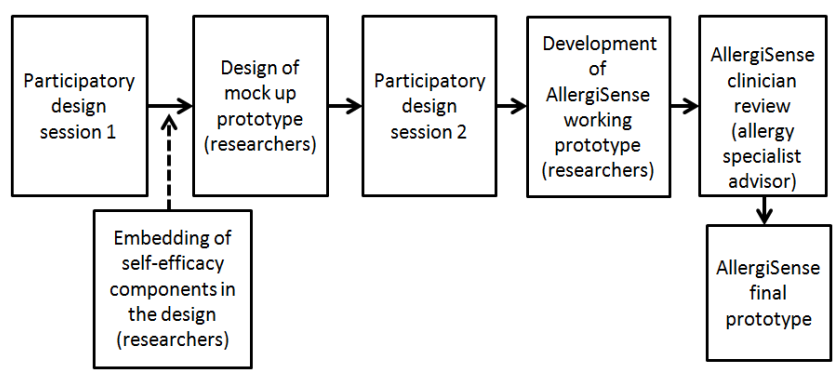

Fig. 1. Participatory design methodology embedded with self-efficacy components.

efficacy sources.

The motivation for incorporating participatory design was to evolve an improved design from a deeper understanding of anaphylaxis management needs and from different perspectives of users and stakeholders. The participatory design process, shown in Fig. 1, comprised two workshop events with expert clinical participants, caregivers for individuals at risk of anaphylaxis, an adult with a history of anaphylaxis, and system designers. Participants identified two main anaphylaxis management contexts: emergency and everyday life. They also identified specific management needs 
including help to educate others, support for AAI use and AAI management, and help with emergency situations. Participants created paper interface prototypes of tools to support these needs using the PICTIVE (Plastic Interface for Collaborative Technology Initiatives through Video Exploration) participatory design approach [47].

a)

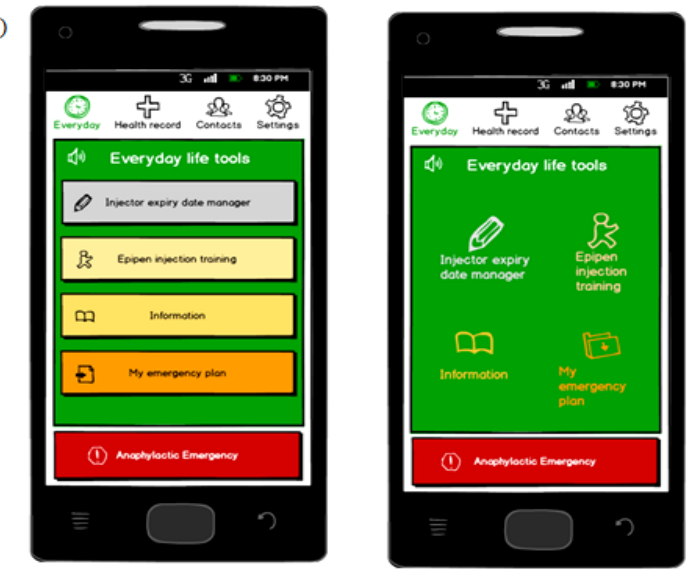

Would you like to see a list of horizontal buttons or icons with labels?

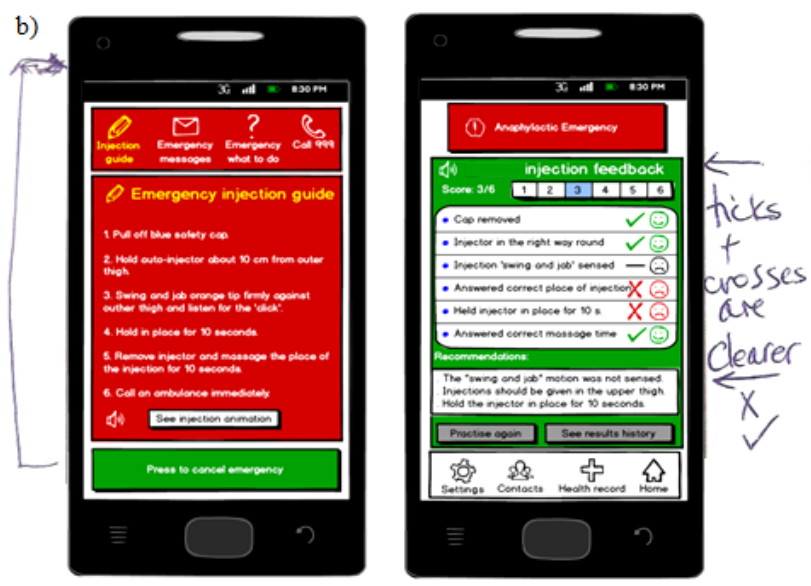

Fig. 2. AllergiSense mock-up prototype screenshots: a) Example of interfaces choices presented to participants: Button vs icon menu styles; b) Examples of participant suggestions (relocation of cancel button to avoid pressing it by mistake; ticks and crosses over emoticons for injection feedback).

In addition to tools explicitly suggested in the participatory design process, an AAI injection training tool was created as a vehicle to increase self-efficacy: encouraging mastery (via performance support) and providing persuasion (via feedback). A simplified injection force-sensing tool had been developed in earlier technology prototyping [38]. The tool was enhanced and a new user interface was included in mock-ups presented at the participatory design session 2 for participant feedback. Interfaces for the full set of tools were mocked-up using Balsamiq ${ }^{\circledR}$ software for higher fidelity user interface prototyping. Fig. 2. shows a) an example of one of the interface design choices presented to participants and b) shows examples of participant preferences. As well as the bold and strictly consistent use of function coloring (red for emergency and green for everyday function), these examples demonstrate ways in which AllergiSense design considerations varied from those of a generic app. With effective and error-free use identified as a top priority; clarity, simplicity and consistency were essential to the interface design. For example, of the choices shown in Fig. 2a, participants preferred the simple button menu style with sympathetic coloring. In Fig. 2b, participant annotations show a preference for the emergency button (and cancel emergency button) at the top of the screen which they said would improve visibility and better avoid pressing it by mistake, and, as shown, ticks and crosses were preferred for clarity in the injection training feedback tool.

\section{ALLERGISENSE IMPLEMENTATION}

\section{A. AllergiSense mobile application tools}

The AllergiSense design and the information content were subject to clinical inspection prior to the production of the final prototype used in the evaluation. AllergiSense was implemented in an Android Smartphone. Example screenshots are shown in Fig. 3. For everyday life, the AllergiSense tools include a list of AAI expiry dates with reminders, videos about anaphylaxis and symptoms, a step-by-step trainer tool showing how to use an EpiPen ${ }^{\circledR}$ AAI, and the AAI trainer tool to provide feedback on the correctness of sensed injection steps. The AAI expiry date tool (Fig. 3d) requires users to initially 'register' the serial number ID and expiry date of each of their AAIs. The shelf life of EpiPen ${ }^{\circledR}$ and Jext ${ }^{\circledR}$ AAIs is 18 months. In part, this tool is equivalent to the alert services provided by these manufacturers which send email or SMS text messages at four months and two months prior to expiry and again one day after expiry. But, as suggested by our design participants, this AllergiSense tool has additional functionality, for example, it stores the usual location of each AAI and provides the number of days before each expires. Green, yellow and red emoticons also summarize the AAI expiry states, namely, "OK", "nearing expiry" and "expired", respectively.

For emergency scenarios, AllergiSense tools include a single-screen emergency 'what to do' list and step-by-step AAI instructions. In addition, AllergiSense emergency messaging tools can send text messages to predefined numbers identifying the user's GPS location, and emergency services can be contacted with the touch of a button.

\section{B. AllergiSense sensing unit}

Fig. 4 shows the sensing unit mounted on an AAI trainer device. It was encased in a slim plastic cover and comprised an Arduino "Pro mini" microcontroller, a 3-axis accelerometer, a push button sensor (to detect removal of the safety cap), a Bluetooth ${ }^{\mathrm{TM}}$ transceiver and a coin cell battery.

The role of the sensing unit was to detect removal of the safety cap and to collect acceleration data. The accelerometer sensor unit was configured to sample $\mathrm{X}, \mathrm{Y}$ and $\mathrm{Z}$ acceleration channels at $70 \mathrm{~Hz}$. This sampling rate was empirically selected as sufficiently high for injection sensing fidelity and sufficiently sustainable in terms of battery life. All data were transmitted to the smartphone using a Serial Port Profile (SPP) and used by the injection feedback training tool to determine if the safety cap had been removed, if the injector was held the right way around, if a 'swing and jab' was performed and if the trainer was held in place for 10 seconds. 


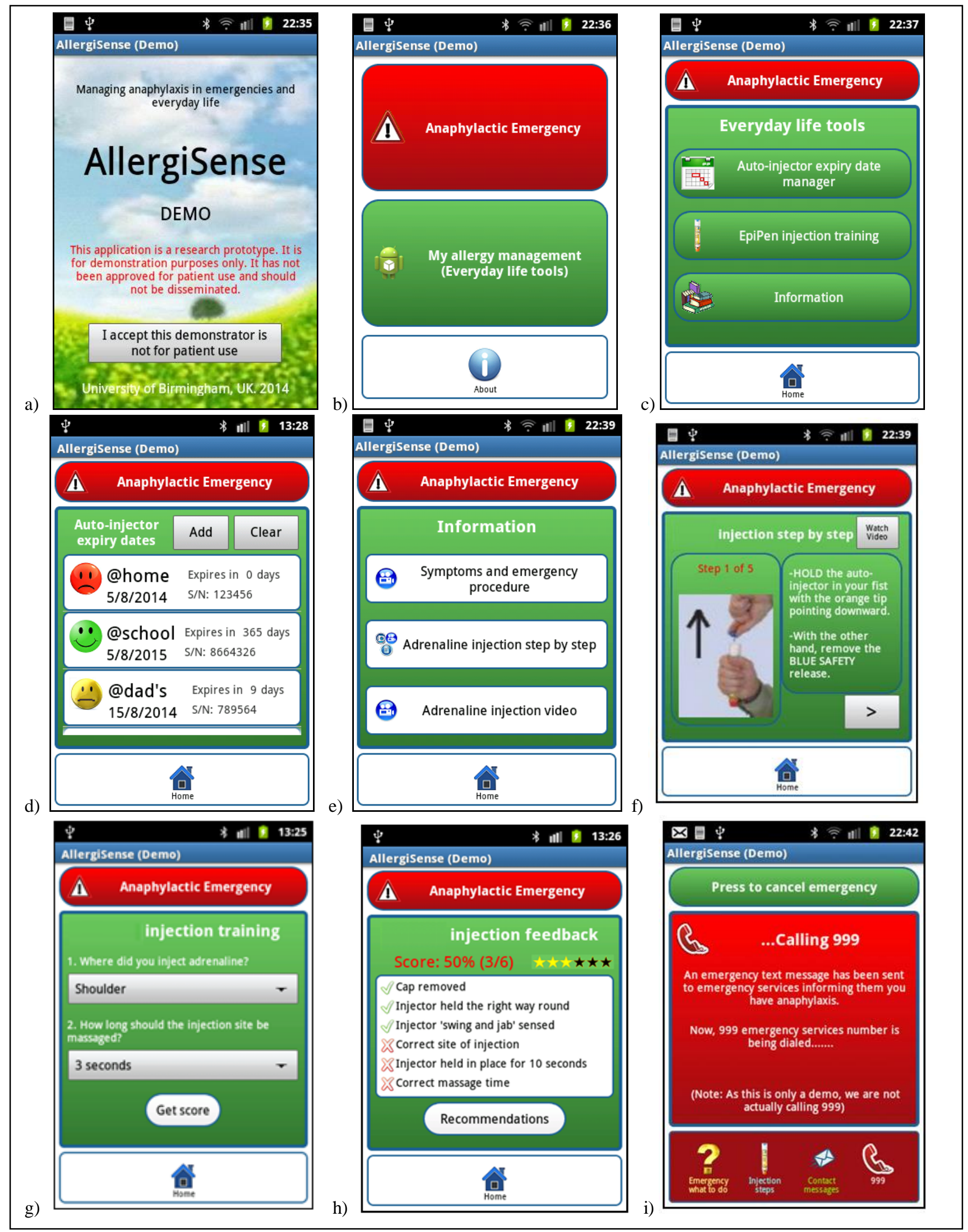

Fig. 3. AllergiSense screenshots: a) Initial screen; b) Emergency and everyday life menu buttons; c) Everyday life tools menu; d) AAI expiry dates list; e) Information menu; f) Injection step-by-step instructions; g) Injection training questions; h) Injection feedback screen (provided after pressing the button 'Get score' in 3g); i) Emergency tools. 


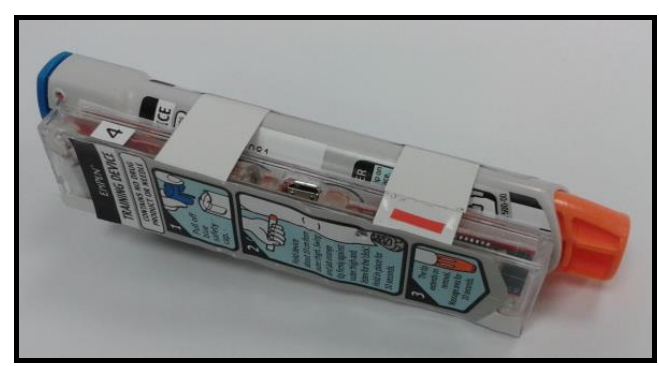

Fig. 4. AllergiSense sensing unit mounted on an EpiPen® AAI trainer device.

The removal of the safety cap was detected directly by the sensor underneath the cap. Two action classes were used to identify the injection steps: "swinging and jabbing" (when delivering the injection) and "still" (when holding the trainer injector in place). A third class, "moving", was defined as any other action. These classes were defined by accelerometer training data from twelve correctly performed injections provided by an allergy clinician. All the clinician's injections were performed with the right hand (the clinician's dominant hand). Six were performed while standing and six while sitting.

Classification was performed using a J48 binary decision tree using accelerometer data features that included the mean, standard deviation, maximum and minimum values, difference between the maximum and minimum values, and the average distance from the mean. J48 is an open source Java implementation of the $\mathrm{C} 4.5$ decision tree algorithm in the WEKA data mining application. This algorithm was chosen for ease of implementation and its robust performance in testing. A correct injection is identified as a sequence of steps in the following order: "moving", "swinging and jabbing", "still" and "moving". The results of testing with participant data were: "swinging and jabbing" was classified with an accuracy of $81 \%$, precision of $96 \%$ and recall of $83 \%$ $($ F-measure $=89 \%)$; "still" was classified with an accuracy of $81 \%$, precision of $83 \%$ and recall of $91 \%$ (F-measure $=87 \%$ ).

\section{AllergiSense injection feedback tool}

The AllergiSense injection feedback tool provides out-ofsix marks for practiced injections as depicted in Fig $3 \mathrm{~h}$. The tool assesses injection site and massage time via two questions with randomly located answers in pull-down menus (shown in Fig. 3g), and the other four assessments (cap removed, injector the right way around, swing and jab, and held in place for 10 seconds) are assessed automatically via the data communicated from the sensing unit.

If users provide incorrect responses or perform erroneous actions these are marked as incorrect as depicted in Fig. 3h, the out-of-six score is deducted accordingly and informative recommendations are provided in a subsequent screen if the user presses the 'Recommendations' button. The recommendation explains how to improve a specific step of the injection and encourages another injection training attempt.

\section{AllergiSense eVAluation}

The AllergiSense adrenaline injection training tool was evaluated with a three-arm, pre-post (two-week), randomized controlled study with sixty-three healthy participants recruited from the University of Birmingham, UK.

The main hypothesis of this evaluation was that using AllergiSense (in addition to traditional training using information leaflets) would enhance adrenaline injection training skills compared to traditional instruction using information leaflets alone. The primary aim of the evaluation was an assessment of the effect of different training materials on practiced adrenaline injection skills. The secondary aim was to evaluate participants' self-reported AAI self-efficacy, workload, system usability, system usefulness, ease-of-use and attitudes towards its use.

The training provided was clinically approved and the procedure overseen by an expert clinical collaborator.

\section{A. Statistics}

A Shapiro-Wilk test was used to test if results were samples of a normally distributed population (Significance level $=0.05$ ) [48]. Parametric t-tests and ANOVA test were used on normally distributed results; Friedman's Rank and Mann-Whitney (U) tests for results not normally distributed and chi-squared test $\left(\chi^{2}\right)$ for comparing frequencies of data. The statistical tests were undertaken using SPSS $®$ version 20.

\section{B. Participants}

Sixty-three student and staff participants aged between 1860 were recruited via email invitation from the University of Birmingham, UK. All participants reported carrying and using mobile phones. Participants were block randomized into three groups of twenty-one participants. The groups comprised participants with broadly equivalent smartphone experience in terms of smartphone usage and number of apps used, and with similar average age and gender balance, and all participants were right-handed. Individuals known to be at risk of anaphylaxis and their caregivers were excluded from the study (their recruitment would have required extensive National Health Service ethical permissions; future approval for testing of new technology with patients would be more likely in the event of positive outcomes from testing with healthy participants).

\section{Assessment of performance and administered questionnaires}

The assessment of AAI performance was based on the four-step marking scheme used in other studies [19], [29], which, in turn, were based on the steps recommended by the EpiPen ${ }^{\circledR}$ AAI manufacturer [49] which are:

1. "Remove the blue safety cap.

2. 'Swing and jab' the orange tip of the AAI trainer against the outer thigh until it 'clicks'.

3. Hold firmly against the thigh for 10 seconds.

4. Remove the auto-injector from the thigh. The orange tip will extend to cover the needle and massage the injection area for 10 seconds." 
The AllergiSense system separates step 2 into two by i) sensing "swing and jab" and ii) explicitly asking the user to select the correct injection site from a randomly ordered list. In addition, AllergiSense senses for the injector being held the right way around. This means that while AllergiSense assesses the four step injection performance, it reports on-screen out of six rather than out of four (Fig. 3h).

The performance of all participants' adrenaline injections was evaluated via video observation of the four recommended steps. An inter-rated test with an independent researcher was carried out with a random sample of injections (Cohen's Kappa > 0.8). Injection step differences were discussed with, and verified by, the independent researcher using the recorded video and sensor data from the AllergiSense sensing unit.

Workload and self-reported usability. NASA TLX [50] and System Usability Scale (SUS) [51] questionnaires were used for evaluation of workload and self-reported usability, respectively. NASA TLX quantifies workload component levels of mental, physical and temporal demands. The SUS questionnaire provides a measure of perceived usability, covering aspects of acceptance, need for support, training and system complexity [52], [53].

Self-efficacy. A self-efficacy questionnaire for adrenaline injection was created using eleven-point (0: Not at all confident - 10: Totally confident) scale responses as recommended by Bandura [54]. The questionnaire comprised statements relevant to the use of AAIs in training and emergencies for participants to rate. For example, "I am confident that I can correctly use an auto-injector trainer in a practice session.", "I am confident I can apply the correct force when injecting", "I am confident I can identify the correct injection site", "I am confident I can correctly use an auto-injector in an allergic emergency" and "I am confident that I would inject correctly in an emergency even if I was very anxious". The selection and phrasing of the questions was first reviewed by allergy clinical collaborators and assessed by eighteen allergy specialists.

Usefulness, ease-of-use and attitudes towards use. Selfreported measures of usefulness, ease of use and willingness regarding use were collected from technology acceptance questionnaires [55].

\section{Materials}

Subsequent to clinically approved training (i.e., allergy specialist's videos about anaphylaxis and EpiPen ${ }^{\circledR}$ use), participants were randomly assigned to one of the three following groups.

Paper (traditional care information with paper leaflets documentation). Participants in all groups received a paper copy of the EpiPen® AAI instruction leaflet (the instructions for use provided in the EpiPen ${ }^{\circledR}$ AAI patient information).
This document provides information about injector use and step-by-step pictures for each of the four injection steps. Participants in the paper-only (control) group received only this information. Participants in the other groups had this material supplemented with AllergiSense materials as described below.

AllergiSense without feedback. Participants in this group received the AllergiSense smartphone system without the injection practice feedback functionality, i.e., AllergiSense without the out-of-six injection practice feedback. Thus participants with AllergiSense without feedback were provided with the paper instructions (the same as the control paper group) supplemented with smartphone video (an instructional Epipen ${ }^{\circledR}$ AAI video produced by the manufacturer and available online on the EpiPen® AAI website) and an AAI step-by step instruction tool (text and pictures as per paper steps depicted in Fig. 3f).

AllergiSense. This was the complete AllergiSense smartphone system using the sensing unit connected to the AllergiSense smartphone and providing out-of-six injection feedback. Thus, participants in this group were provided paper instructions (the same as the control paper group) supplemented with smartphone AAI step-by-step instructions (Fig. 3f) and an AAI usage video (the same as the AllergiSense without feedback) and the mark out-of-six injection feedback (Fig. 3h).

All the three groups used the same AllergiSense sensing unit depicted in Fig. 4. All sensor data for all participants in all groups was logged and recorded during the experimental sessions. Data from the paper-only group and the AllergiSense without feedback group were recorded via HyperTerminal for research records. While the data of the AllergiSense group were recorded in the smartphone. Participants in the AllergiSense group were the only people that received feedback about their training injections.

\section{E. Experimental procedure}

The experiment comprised two sessions, two weeks apart. In session one, participants were randomly allocated to one of the three groups. All participants received the same clinically approved training with videos of an allergy specialist using an EpiPen ${ }^{\circledR}$ AAI trainer. Participants were then asked to demonstrate an injection of adrenaline with the trainer device (Demonstration 1), and were then provided with one of three different training materials described earlier: paper-only, AllergiSense without feedback or AllergiSense. Participants were then required to practice three injections using their allocated training materials before completing a demonstration injection (Demonstration 2). In session two, two weeks later, participants were recalled to demonstrate their injection skills (Demonstration 3) then practice three injections using their allocated training material before completing a final demonstration injection (Demonstration 4). 
Only the participants in the AllergiSense group received feedback on their injection performance (from the injection feedback training tool - Fig. 3h). All other participants received no feedback on their injections until they were provided with an account during the experimental debrief at the end of session two. None of the participants reported extra training between sessions.

\section{RESULTS}

Table I shows the number of participants in each group that correctly completed the four injection steps. Only $28.6 \%$ of the paper-only group correctly completed all four injection steps in their final demonstration vs. $66.7 \%$ for AllergiSense without feedback and $90.5 \%$ for AllergiSense. Although more people in the AllergiSense group performed all steps correctly after the initial training (i.e., in Demonstration 1), there were no significant differences between groups: 5 vs $4(p=0.707)$, 5 vs $7(p=0.495)$ and 4 vs $7(p=0.242)$. Similarly, after training in session 1 (i.e., in Demonstration 2) although more people in the AllergiSense group correctly completed all the steps, there were no significant differences between the groups: 5 vs $9(p=0.19), 5$ vs $10(p=0.107)$ and 9 vs 10 $(p=0.757)$. However, after training in session 2 (i.e., in Demonstration 4) significantly more people in the AllergiSense and AllergiSense without feedback groups completed the four steps correctly compared to the control (paper-only) group: 6 vs $19(p<0.001)$ and 6 vs 14 $(p=0.013)$ respectively, while the difference between AllergiSense without feedback and AllergiSense showed a trend towards significance: 14 vs $19 \quad(p=0.060)$. The AllergiSense group improved significantly after training in session 2, from 9 to 19 of 21 participants injecting without error $(p=0.013)$, and the AllergiSense without feedback group showed a trend towards significance: from 8 to 14 of 21 participants injecting without error $(p=0.064)$.

TABLE I

PRIMARY OUTCOME: NUMBER OF PEOPLE CORRECTLY COMPLETING THE FOUR INJECTION STEPS

\begin{tabular}{ccccc}
\hline \hline Group & \multicolumn{2}{c}{ Session 1 } & \multicolumn{2}{c}{ Session 2 } \\
\hline & $\begin{array}{c}\text { Demonstration } \\
1 \\
\text { (after } \\
\text { watching } \\
\text { clinical video) }\end{array}$ & $\begin{array}{c}\text { Demonstration } \\
\text { (after training) }\end{array}$ & $\begin{array}{c}\text { Demonstration } \\
3 \\
\text { (after two } \\
\text { weeks) }\end{array}$ & $\begin{array}{c}\text { Demonstration } \\
4 \\
\text { tainter } \\
\text { traing) }\end{array}$ \\
\hline $\begin{array}{c}\text { 1.Paper-only } \\
\text { 2.AllergiSense } \\
\text { without } \\
\text { feedback }\end{array}$ & 4 & 5 & 8 & 6 \\
3.AllergiSense & $(19.0 \%)$ & $(42.9 \%)$ & $(38.1 \%)$ & $(66.7 \%)$ \\
\hline \hline
\end{tabular}

In contrast, the paper-only group actually deteriorated in session 2: from 8 to 6 of 21 participants injecting correctly, and across the four demonstrations there was no significant change in this group's injection ability despite the training opportunities $(p>0.05)$.

For the two AllergiSense groups the number of errors made decreased with training. The total number of injection errors from all four demonstrations of the three groups was 225 (from a theoretical maximum of 1008 errors $=63$ [participants] $\times 4$ [possible errors] $\times 4$ [demonstrations]). Only $3.1 \%$ of all errors involved a failure to remove the safety cap and all of these occurred in Demonstration 1. Not massaging the injection site for 10 seconds comprised $52.9 \%$ of all errors, not injecting with sufficient force comprised $24.9 \%$ and not holding the AAI trainer in place for 10 seconds comprised the remaining $19.1 \%$ of all errors.

In Demonstration 2 more participants in the paper-only group injected with sufficient force in comparison with the AllergiSense groups, but the difference was not significant $(p>0.05)$. However, at the end of the study (Demonstration 4) both AllergiSense groups made significantly less errors in this step than the paper-only group. More participants in both AllergiSense groups held the AAI trainer in place for 10 seconds in all four of their demonstrations, compared with the paper-only group. After training with their allocated material, in Demonstration 2 and Demonstration 4, more people in both AllergiSense groups massaged the injection site for 10 seconds and made significantly less errors in this step at the end of the two-week study in comparison with the paper-only group.

TABLE II

SECONDARY OUTCOMES: SELF-EFFICACY, USEFULNESS, EASE-OF-USE, ATTITUDES TOWARDS USE, SYSTEM USABILITY AND WORKLOAD

\begin{tabular}{|c|c|c|c|c|}
\hline & & $\begin{array}{c}\text { Group } 1 \\
\text { Paper-only }\end{array}$ & $\begin{array}{c}\text { Group } 2 \\
\text { AllergiSense } \\
\text { without } \\
\text { feedback }\end{array}$ & $\begin{array}{c}\text { Group } 3 \\
\text { AllergiSense }\end{array}$ \\
\hline \multirow{2}{*}{$\begin{array}{l}\text { Self-efficacy after } \\
\text { Demonstration } 1 \\
\quad(\text { session } 1)\end{array}$} & $\begin{array}{l}\text { Average } \\
\text { score }\end{array}$ & 7.5 & 7.6 & 7.1 \\
\hline & $\begin{array}{l}\text { Standard } \\
\text { deviation }\end{array}$ & 1.4 & 1.2 & 1.4 \\
\hline \multirow{2}{*}{$\begin{array}{l}\text { Self-efficacy after } \\
\text { Demonstration } 2 \\
\quad(\text { session } 1)\end{array}$} & $\begin{array}{l}\text { Average } \\
\text { score }\end{array}$ & 8.5 & 8.6 & 8.5 \\
\hline & $\begin{array}{l}\text { Standard } \\
\text { deviation }\end{array}$ & 1.2 & 1.0 & 0.9 \\
\hline \multirow{2}{*}{$\begin{array}{l}\text { Self-efficacy after } \\
\text { Demonstration } 3 \\
\quad(\text { session } 2)\end{array}$} & $\begin{array}{l}\text { Average } \\
\text { score }\end{array}$ & 8.5 & 8.7 & 8.4 \\
\hline & $\begin{array}{l}\text { Standard } \\
\text { deviation }\end{array}$ & 1.4 & 1.1 & 1.0 \\
\hline \multirow{2}{*}{ Usefulness } & $\begin{array}{l}\text { Average } \\
\text { score }\end{array}$ & 5.1 & 6.1 & 6.2 \\
\hline & $\begin{array}{l}\text { Standard } \\
\text { deviation }\end{array}$ & 1.5 & 0.6 & 1.0 \\
\hline \multirow{2}{*}{ Ease-of-use } & $\begin{array}{l}\text { Average } \\
\text { score }\end{array}$ & 4.7 & 6.2 & 6.0 \\
\hline & $\begin{array}{l}\text { Standard } \\
\text { deviation }\end{array}$ & 1.5 & 0.6 & 1.0 \\
\hline \multirow{2}{*}{$\begin{array}{c}\text { Attitudes towards } \\
\text { use }\end{array}$} & $\begin{array}{l}\text { Average } \\
\text { score }\end{array}$ & 5.1 & 6.1 & 6.1 \\
\hline & $\begin{array}{l}\text { Standard } \\
\text { deviation }\end{array}$ & 1.1 & 0.6 & 0.7 \\
\hline \multirow{2}{*}{$\begin{array}{c}\text { System Usability } \\
\text { Scale (SUS) }\end{array}$} & $\begin{array}{l}\text { Average } \\
\text { score }\end{array}$ & 68.5 & 86.3 & 82.7 \\
\hline & $\begin{array}{l}\text { Standard } \\
\text { deviation }\end{array}$ & 14.5 & 9.0 & 15.9 \\
\hline \multirow{2}{*}{$\begin{array}{c}\text { Workload } \\
\text { (NASA TLX) }\end{array}$} & $\begin{array}{l}\text { Average } \\
\text { score }\end{array}$ & 34.1 & 31.9 & 31.5 \\
\hline & $\begin{array}{l}\text { Standard } \\
\text { deviation }\end{array}$ & 17.1 & 13.9 & 12.2 \\
\hline
\end{tabular}

Table II shows the questionnaire results for self-efficacy, usefulness, ease-of-use, attitudes towards use, system usability and workload. Self-efficacy differences within groups were seen after training with their allocated material in session 1 (From Demonstration 1 to Demonstration 2). The self-efficacy of the paper-only group increased from 7.5 to $8.5(p<0.001)$, the AllergiSense without feedback group increased from 7.6 to $8.6(p<0.001)$ and the AllergiSense group increased from 7.1 to $8.5(p<0.001)$. Self-efficacy remained high for the three 
groups for two weeks, and no significant differences were found between the three groups $(p>0.05)$.

After using their allocated material in session 1 (after Demonstration 2), participants in both the AllergiSense and AllergiSense without feedback groups reported significantly higher average scores for the usefulness, the ease-of use and in the willingness to use their training materials compared to the paper-only group as follows. Usefulness: 5.1 (paper) vs 6.1 (AllergiSense without feedback) $(p=0.012) ; 5.1$ (paper) vs 6.1 (AllergiSense) ( $p=0.001)$; Ease-of-use: 4.7 (paper) vs 6.2 (AllergiSense without feedback) $(p=0.001) ; 4.7$ (paper) vs 6.0 (AllergiSense) $(p=0.005)$; Willingness towards use: 5.1 (paper) vs 6.1 (AllergiSense without feedback) $(p<0.001)$ and 5.1 (paper) vs 6.1 (AllergiSense) $(p<0.001)$. While there were slightly, but not significant differences between AllergiSense and AllergiSense without feedback in the levels of usefulness, ease-of-use, attitudes towards use and SUS scores.

In addition, both AllergiSense groups reported significantly higher system usability scores (SUS), after Demonstration 2, than the paper-only group: 68.5 (paper) vs 86.3 (AllergiSense without feedback) $\quad(p<0.001) ; 68.5 \quad$ (paper) $\quad$ vs 82.7 (AllergiSense) $(p=0.001)$. While the workload, reported after Demonstration 4, was not significantly different between groups $(p=0.991)$.

\section{DISCUSSION OF RESULTS}

While the results of small studies should, necessarily, be interpreted cautiously, the results presented here provide a measure of evidence toward the hypothesis that smartphone tools supplementing traditional instruction paper leaflets could improve adrenaline injection training skills.

The improved results for AllergiSense could be a consequence of improved training from the explicit and purposeful reinforcement of self-efficacy via mastery, vicarious and social experiences embedded within videos, step-by-step instructions and visual feedback. Where, in contrast, paper instructions provide only limited modeling opportunities from text and pictures. There was no significant improvement in the performance of the paper-only group throughout the study.

The results appear to support other reports in the literature [19]-[29] regarding the inadequacy of the current approach to adrenaline injection education (i.e., expert explanation and AAI demonstration). Current instruction, where the use of AAIs is just demonstrated does not include provision for feedback, nor encouragement nor support of continuous practice. This was observed after Demonstration 1 (after the clinically-approved training) when, at best, only one third of people in the three groups could correctly complete all four steps of the injection $(23.8 \%, 19 \%$ and $33.3 \%$ for control, AllergiSense without feedback and AllergiSense, respectively). These very low results concur with other extremely poor findings reported in the literature.
One interesting and unexpected result was the significant increase in self-efficacy in the paper-only group after first use of their material for training (after Demonstration 2). This increase was less than the increase for the AllergiSense groups but not significantly so. The paper-only group retained their increased self-efficacy throughout the study despite the lack of any significant improvement in their performance. This was exemplified at the end of session 2 by one paper-only participant who had made no correct injection demonstrations at all, but expressed surprise for each when informed of the results. Bandura [56] has reported that improved self-efficacy in the absence of improved performance indicates a problem in the system. Perhaps then, the experiment revealed something of the problem with the current system, i.e., that in the absence of monitoring and feedback people have elevated self-efficacy based on incorrect assumptions about their mastery skills. This could have several consequences, not least the lack of motivation for continuous practice.

Secondary outcome results showed that participants reported no significant differences in workload for the three different training materials. Interestingly, compared to the paper-only group both AllergiSense groups scored significantly better for usefulness and ease-of-use of their materials and also reported significantly more willingness towards use. Additionally, average self-reported usability scores (SUS) for both AllergiSense groups were very positive. The paper-only participants reported, according to Bangor et al.'s adjective scale [57, p. 592], a marginally acceptable SUS score of 68.45 (between OK and good), while the SUS score for AllergiSense without feedback was 86.31 and was 82.74 for AllergiSense (both between good and excellent). Although the AllergiSense without feedback group reported slightly better levels of ease-of-use and SUS scores, and that the AllergiSense group reported slightly better levels of usefulness and workload, they were not significantly different. These results may be an indication that the use of the full AllergiSense system (smartphone and sensing unit) did not have a substantial impact on self-reported usability measures, despite the AllergiSense group carried out more elaborated training tasks.

Results showed that adrenaline injection self-efficacy improved after the first training session and then was not significantly different two weeks later. Perhaps if participants had been recalled six weeks or six months later these selfefficacy results might be substantially different. Further work involving longer-term studies is recommended to investigate how self-efficacy and adrenaline injection skills attenuate over time and how these are impacted by the training materials used.

This research was limited to short-term evaluations with healthy participants. Thus, in every aspect of the work presented here there is scope for further contribution. Children are most affected by anaphylaxis and the most common allergen, peanuts, is not generally outgrown. This new generation will need support in the management of their anaphylaxis. We hope that the results presented here will encourage further technology research and development in 
support of anaphylaxis management. For example, further work is also needed to populate solutions with content and define tools aimed at supporting symptom recognition and allergen avoidance. Further work could also consider the issues of responsibility for the support and maintenance of the technology and the information contained within it. In addition, further work is needed for the creation and validation of self-efficacy questionnaires for anaphylaxis management and adrenaline injection and, importantly, much further work is needed for evaluation of tools in longitudinal studies with patients in and outside the clinic.

\section{CONCLUSIONS}

This paper provided experimental evidence supporting the potential of smartphone tools and wireless sensors to significantly improve AAI training skills, usefully supplement traditional care paper information leaflets and positively influence injection training performance and user's selfefficacy. The study was limited to a randomized, controlled, pre-post intervention with healthy participants simulating adrenaline injections with an AAI trainer, but still the results provided valuable insights and proof-of-concept evidence to support a case for future clinical trials implementing the technology with both physicians and patients.

It was noted that participants in the control group, trained with traditional care paper information leaflets alone, did not improve their AAI performance and made persistent errors in administration of the AAI throughout training practice. Notwithstanding the poor AAI skills exhibited by the paperonly group, the results revealed that their levels of selfefficacy increased, despite being wholly incompatible with their actual AAI skills. Whilst it is important to be cautious in the interpretation of these data given the limited participant numbers, this finding was interesting and unexpected. It may provide an insight into deficits in AAI use. Incorrect assumptions behind inappropriately elevated self-efficacy could be a consequence of the lack of AAI training monitoring and feedback and suggests that it is difficult to identify one's own errors and assess one's own competence. This could have several consequences, not least complacency regarding AAI training and a lack of motivation for continuous practice.

The injection sensing implemented in AllergiSense performed robustly throughout all evaluations presented here. However, in a subsequent qualitative evaluation study in which AllergiSense was provided to expert allergy physicians and nurses, further improvements were identified. For example, the expansion of the training data to include different injection scenarios, such as injecting while lying down. Improved sensing in realistic scenarios could also be useful in prototyping new "smart" AAI designs with emergency AAI sensing capability. Further research in support of anaphylaxis management may have positive implications since people with anaphylaxis and their caregivers are motivated more than most to learn how to use AAIs, and carry smartphones because they may need to make emergency calls, and so the technology platform needed for an assistive healthcare solution is already available.

\section{ACKNOWLEDGMENT}

The authors gratefully acknowledge the institutions that funded and supported this research, the expertise and support of the Anaphylaxis Campaign UK, and the clinicians and staff at hospital trusts: University Hospitals of Leicester NHS Trust, University Hospitals Birmingham NHS Foundation Trust, Heart of England NHS Foundation Trust, Worcestershire Acute Hospitals NHS Trust and Sandwell \& West Birmingham Hospitals NHS Trust. We also thank our editor and our reviewers since their suggestions and comments greatly improved this paper.

\section{REFERENCES}

[1] H. A. Sampson, A. Munoz-Furlong, R. L. Campbell, N. F. Adkinson, S. A. Bock, A. Branum, S. G. A. Brown, C. A. Camargo, R. Cydulka, S. J. Galli, J. Gidudu, R. S. Gruchalla, A. D. Harlor, D. L. Hepner, L. M. Lewis, P. L. Lieberman, D. D. Metcalfe, R. O'Connor, A. Muraro, A. Rudman, C. Schmitt, D. Scherrer, E. R. Simons, S. Thomas, J. P. Wood and W. W. Decker, "Second Symposium on the Definition and Management of Anaphylaxis: Summary report - Second National Institute of Allergy and Infectious Disease/Food Allergy and Anaphylaxis Network Symposium", Annals of Emergency Medicine, vol. 47, no. 4, pp. 373-380, 2006.

[2] F. E. R. Simons and H. A. Sampson, "Anaphylaxis epidemic: fact or fiction?", Journal of Allergy and Clinical Immunology, vol. 122, no. 6, pp. 1166-8, Dec. 2008.

[3] P. Lieberman, C. A. Camargo, K. Bohlke, H. Jick, R. L. Miller, A. Sheikh, and E. R. Simons, "Epidemiology of anaphylaxis: findings of the American College of Allergy, Asthma and Immunology Epidemiology of Anaphylaxis Working Group", Annals of Allergy, Asthma and Immunology, vol. 97, no. 5, pp. 596-602, 2006.

[4] P. Lieberman, "Epidemiology of anaphylaxis", Current Opinion in Allergy and Clinical Immunology, vol. 8, no. 4, pp. 316-320, 2008.

[5] F. E. R. Simons, "World Allergy Organization survey on global availability of essentials for the assessment and management of anaphylaxis by allergy-immunology specialists in health care settings", Annals of Allergy, Asthma \& Immunology vol. 104, no. 5, pp. 405-412.2010.

[6] C. Editors, P. Lieberman, S. F. Kemp, J. Oppenheimer, J. N. Fink, P. A Greenberger, K. Dennis, J. Li, A. L. Sheffer, R. Solensky, and B. L. Wolf, "The diagnosis and management of anaphylaxis: an updated practice parameter", Journal of Allergy and Clinical Immunology, vol. 115, no. 3 Suppl 2, pp. S483-523, Mar. 2005.

[7] F. E. R. Simons, L. R. F. Ardusso, M. B. Bilò, V. Dimov, M. Ebisawa, Y. M. El-Gamal, D. K. Ledford, R. F. Lockey, J. Ring, M. SanchezBorges, G. E. Senna, A. Sheikh, B. Y. Thong, and M. Worm, "2012 Update: World Allergy Organization Guidelines for the assessment and management of anaphylaxis”, World Allergy Organization, vol. 12, no. 4, pp. 13-37, Aug. 2011.

[8] K. J. Allen, D. J. Hill, and R. G. Heine, "Food allergy in childhood", Medical Journal of Australia, vol. 185, no. 7, pp. 394-400, 2006.

[9] NICE, "Anaphylaxis. Assessment to confirm an anaphylactic episode and the decision to refer after emergency treatment for a suspected anaphylactic episode", 2011.

[10] Anaphylaxis101 (Mylan), “Anaphylaxis101 app,” October, 2012. [Online]. Available:

https://play.google.com/store/apps/details?id=com.aurasma.skinned.ana phylaxis101\&hl=en_GB. [Accessed: 14-Jun-2014].

[11] A. Muraro, G. Roberts, A. Clark, P. A. Eigenmann, S. Halken, G. Lack, A. Moneret-Vautrin, B. Niggemann, and F. Rancé, "The management of anaphylaxis in childhood: position paper of the European academy of allergology and clinical immunology", Allergy, vol. 62, no. 8, pp. 857-71, Aug. 2007.

[12] S. Walker and a Sheikh, "Managing anaphylaxis: effective emergency and long-term care are necessary", Clinical and Experimental Allergy, vol. 33, no. 8, pp. 1015-8, Aug. 2003.

[13] J. Wang, "Management of the patient with multiple food allergies" Current Allergy and Asthma Reports, vol. 10, no. 4, pp. 271-277, 2010.

[14] T. Umasunthar, J. Leonardi-Bee, M. Hodes, P. J. Turner, C. Gore, P. Habibi, J. O. Warner, and R. J. Boyle, "Incidence of fatal food 
anaphylaxis in people with food allergy: a systematic review and metaanalysis", Clinical and Experimental Allergy, vol. 43, no. 12, pp. 133341, Dec. 2013.

[15] F. E. R. Simons, "Anaphylaxis: Recent advances in assessment and treatment", The Journal of Allergy and Clinical Immunology, vol. 124, no. 4, Elsevier Ltd, pp. 625-36; quiz 637-8, Oct-2009.

[16] American Academy of Allergy, Asthma \& Immunology, "AAAAI, emergency action plan" 2013. [Online]. Available: https://www.aaaai.org/Aaaai/media/MediaLibrary/PDF

Documents/Libraries/Anaphylaxis-Emergency-Action-Plan.pdf. [Accessed: 01-Dec-2013].

[17] BSACI, "BSACI Allergy Action Plan", 2014. [Online]. Available: http://www.bsaci.org/about/download-paediatric-allergy-actionplans?EID=33016898\&CID=5385780. [Accessed: 20-Jun-2014].

[18] P. Lieberman, R. A. Nicklas, J. Oppenheimer, S. F. Kemp, D. M. Lang, D. I. Bernstein, J. a Bernstein, a W. Burks, A. M. Feldweg, J. N. Fink, P. a Greenberger, D. B. K. Golden, J. M. James, D. K. Ledford, A. L. Sheffer, J. Blessing-Moore, L. Cox, D. a Khan, D. Lang, J. M. Portnoy, C. Randolph, D. E. Schuller, S. L. Spector, S. Tilles, and D. Wallace, "The diagnosis and management of anaphylaxis practice parameter: 2010 update", Journal of Allergy and Clinical Immunology, vol. 126, no. 3, pp. 477-80.e1-42, Sep. 2010.

[19] M. Arga, A. Bakirtas, F. Catal, O. Derinoz, K. Harmanci, C. H. Razi, S. Ergöcen, M. S. Demirsoy, and I. Turktas, "Training of trainers on epinephrine autoinjector use", Pediatric Allergy and Immunology, pp. 1-4, Feb. 2011.

[20] J. Brown, D. Tuthill, M. Alfaham, and E. Spear, "A randomized maternal evaluation of epinephrine autoinjection devices", Pediatric Allergy and Immunology, vol. 24, no. 2, pp. 173-7, Mar. 2013.

[21] S. K. Carlisle, P. A. Vargas, S. Noone, P. Steele, S. H. Sicherer, A. Wesley-Burks, and S. M. Jones, "Food allergy education for school nurses: a needs assessment survey by the consortium of food allergy research", Journal of School Nursing, vol. 26, no. 5, pp. 360-367, 2010.

[22] L. Diwakar, J. Heslegrave, A. G. Richter, A. P. Huissoon, and M. T. Krishna, "Self-injectable adrenaline devices: is training necessary?", Journal of Investigational Allergology \& Clinical Immunology, vol. 20, no. 5, pp. 446-453, 2010.

[23] M. Gallagher, A. Worth, S. Cunningham-Burley, and A. Sheikh, "Epinephrine auto-injector use in adolescents at risk of anaphylaxis: a qualitative study in Scotland, UK", Clinical \& Experimental Allergy, vol. 41 , no. 6 , pp. 869-877, 2011.

[24] H. M. Luckhurst, D. Tuthill, J. Brown, E. Spear, and J. Pitcher, "Anapen, EpiPen and Jext auto-injectors; assessment of successful use after current training package", Archives of Disease.in Childhood, vol. 98, no. Suppl 1, pp. A42-A43, Jun. 2013.

[25] C. Macadam, J. Barnett, G. Roberts, G. Stiefel, R. King, M. ErlewynLajeunesse, J.A. Holloway, and J. S. Lucas, "What factors affect the carriage of epinephrine auto-injectors by teenagers?", Clinical and Translational Allergy, vol. 2, no. 1, p. 3, Jan. 2012.

[26] S. Mehr, M. Robinson, and M. Tang, "Doctor - how do I use my EpiPen?", Pediatric Allergy and Immunology, vol. 18, no. 5, pp. 448452, 2007.

[27] N. U. Nguyen-Luu, L. Cicutto, L. Soller, L. Joseph, S. Waserman, Y. St-pierre, and A. Clarke, "Management of anaphylaxis in schools: Evaluation of an epinephrine auto-injector ( EpiPen W ) use by school personnel and comparison of two approaches of soliciting participation" Allergy, Asthma and Clinical Immunology pp. 1-8, 2012.

[28] L. Noimark, J. Wales, G. Du Toit, C. Pastacaldi, D. Haddad, J. Gardner, W. Hyer, G. Vance, C. Townshend, M. Alfaham, P. D. Arkwright, R. Rao, S. Kapoor, a Summerfield, J. O. Warner, and G. Roberts, "The use of adrenaline autoinjectors by children and teenagers", Clinical \& Experimental Allergy, vol. 42, no. 2, pp. 28492, Feb. 2012.

[29] S. H. Sicherer, J. A. Forman, and S. A. Noone, "Use Assessment of Self-Administered Epinephrine among Food-Allergic Children and Pediatricians", Pediatrics, vol. 105, no. 2, pp. 359-362, 2000.

[30] P. D. Arkwright and A. J. Farragher, "Factors determining the ability of parents to effectively administer intramuscular adrenaline to food allergic children". Pediatric allergy and immunology, vol. 17, no. 3, pp. 227-229, 2006

[31] S. Mehr, M. Robinson, T. M. Doctor, S. Mehr, and M. Robinson, "Doctor - How do I use my EpiPen?", Pediatric Allergy and Immunology, no. 6, pp. 448-452, 2007.
[32] B.M. Patel, P. J. Bansal, and M. C. Tobin, "Management of anaphylaxis in child care centers: evaluation 6 and 12 months after an intervention program", Annals of Allergy, Asthma \& Immunology, vol. 97, no. 6, pp. 813-5, Dec. 2006.

[33] A. J. Frew, "What are the 'ideal' features of an adrenaline (epinephrine) auto-injector in the treatment of anaphylaxis?" Allergy, vol. 66, no. 1, pp. 15-24, Jan. 2011.

[34] B. S. Fjeldsoe, A. L. Marshall, and Y. D. Miller, "Behavior change interventions delivered by mobile telephone short-message service", American Journal of Preventive Medicine, vol. 36, no. 2, pp. 165-173, Feb. 2009.

[35] C. Free, G. Phillips, L. Galli, L. Watson, L. Felix, P. Edwards, V. Patel, and A. Haines, "The effectiveness of mobile-health technology-based health behaviour change or disease management interventions for health care consumers: a systematic review", PLoS Med., vol. 10, no. 1, p. e1001362, Jan. 2013.

[36] J. M. Belisario, "Smartphone and tablet self-management apps for asthma", The Cochrane Library, no. 11, 2013.

[37] G. Agnes, A. Muaremi, V. Osmani, G. Bahle, S. Ohler, G. Troster, O. Mayora, C. Haring, P. Lukowicz. "Smartphone-based recognition of States and state changes in bipolar disorder patients." IEEE Journal of Biomedical and Health Informatics, 19, no. 1 (2015): 140-148.

[38] L. U. Hernandez-Munoz and S. I. Woolley, "Mobile Phone Tools with Ambient Intelligence for the Management of Life-Threatening Allergies," in Human Aspects in Ambient Intelligence, vol. 8, T. Bosse, D. J. Cook, M. Neerincx, and F. Sadri, Eds. Paris: Atlantis Press (SpringeLinkr), 2013, pp. 153-172.

[39] Coventry University, "Anaphylaxis," 2013. [Online]. Available: https://itunes.apple.com/gb/app/anaphylaxis/id583861393?mt=8. [Accessed: 15-Jun-2014].

[40] Jext (ALK-Abelló), “Jext app," June, 2013. [Online]. Available: https://play.google.com/store/apps/details?id=com.androidapp.alkabello .jext_uk\&hl=en_GB. [Accessed: 14-Jun-2014].

[41] Auvi-Q (Sanofi-Aventis U.S. LLC), “Auvi-Q app,” February, 2013. [Online]. Available:

https://play.google.com/store/apps/details?id=com.sanofiaventis.AuviQ Companion. [Accessed: 14-Jun-2014].

[42] B. J. Visser, D. A. Korevaar, and T. Nolan, "Mobile medical apps: dangers and potential solutions", Journal of Telemedicine and Telecare, pp. 1-2, Mar. 2013.

[43] M. McCartney, "How do we know whether medical apps work?", BMJ, no. 346, 2013.

[44] A. Bandura, "Self-efficacy: Toward a unifying theory of behavioral change", Psychological Review, vol. 84, pp. 191-215, 1977.

[45] K. Glanz and D. B. Bishop, "The role of behavioral science theory in development and implementation of public health interventions", Annual Review of Public Health, vol. 31, pp. 399-418, Jan. 2010.

[46] L. U. Hernandez-Munoz, S. I. Woolley and L. Diwakar, "Pilot Evaluation of Smartphone Technology for Adrenaline Injection Training", in The British Society for Allergy and Clinical Immunology -BSCAI- Annual Meeting, 2014.

[47] M. J. Muller, "PICTIVE - An Exploration in Participatory Design", in Proceedings of the SIGCHI Conference on Human Factors in Computing Systems, 1991, pp. 225-231.

[48] A. Field, Discovering statistics using SPSS for Windows, London: SAGE Publications Ltd, 2000.

[49] Meda, "Epipen," 2014. [Online]. Available: http://www.epipen.co.uk. [Accessed: 15-Jan-2014].

[50] NASA, "NASA TLX: Task Load Index," NASA. 01-Dec-2003.

[51] J. Brooke, "System Usability Scale," Usabilitynet.org, 01-Dec-2006. [Online]. Available: www.usabilitynet.org/trump/documents/Suschapt.doc. [Accessed: 01Jun-2006].

[52] M. Jones and G. Marsden, Mobile Interaction Design, London: John Wiley \& Sons, Ltd, 2006.

[53] J. Preece, Y. Rogers, and H. Sharp, Interaction design, beyond humancomputer interaction, New York: Wiley \& Sons, Inc., 2002.

[54] A. Bandura, "Guide for constructing self-efficacy scales", in SelfEfficacy Beliefs of Adolescents, 2006, pp. 307-337.

[55] F. D. Davis, "Perceived Usefulness, Perceived Ease of Use, and User Acceptance of Information Technology," Management Information Systems, vol. 13, no. 3, pp. 319-340, 1989.

[56] A. Bandura, "On the Functional Properties of Perceived Self-Efficacy Revisited", Journal of Management, vol. 38, no. 1, pp. 9-44, Sep. 2012. 
[57] A. Bangor, P. T. Kortum, and J. T. Miller, "An Empirical Evaluation of the System Usability Scale", International Journal of Human Computer Interaction, vol. 24, no. 6, pp. 574-594, Jul. 2008.

\section{BIOGRAPHIES}

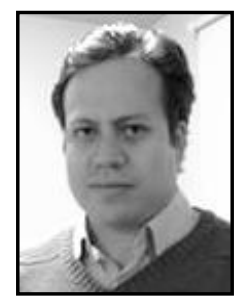

Luis U. Hernandez-Munoz is an IEEE Graduate member and obtained his $\mathrm{PhD}$ from the School of Electronic, Electric and Systems Engineering at the University of Birmingham, UK. His $\mathrm{PhD}$ research was related to pervasive computing for anaphylaxis management. He also has a BSc in Electrical and Electronics Engineering (hons) from the National Autonomous University of Mexico. His current research involves assistive technologies for healthcare, m-health, human-centered design, technology innovation, internet-of-things and studies of usability, effectiveness and acceptance of technology.

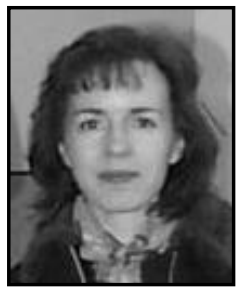

Sandra I. Woolley is an IEEE Senior member and a lecturer in the School of Electronic, Electrical and Systems Engineering at The University of Birmingham, UK. She trained as a graduate engineer with Lucas Aerospace, UK and received a $\mathrm{PhD}$ degree in Electronic Engineering from The University of Manchester before working as a researcher at the National Institute of Standards and Technology (NIST), Maryland, U.S.A. Her current research interests include aspects of e-health and, in particular, applications in rehabilitation and assistive technology.

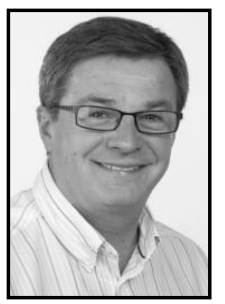

David Luyt is a Consultant Pediatrician at the University Hospitals of Leicester. He completed his undergraduate medical and postgraduate pediatric studies at the University of the Witwatersrand in Johannesburg, South Africa. After qualifying as a pediatrician he undertook a research fellowship in Leicester from which he obtained a Doctor of Medicine from the University of Leicester. $\mathrm{He}$ is the lead consultant in the Children's Allergy Service in Leicester since 1996 and a lead allergy clinician in the UK.

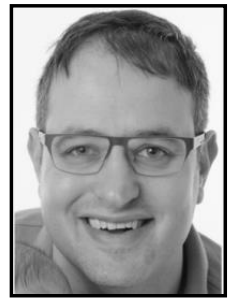

Gary Stiefel is a Consultant in Pediatric Allergy at the University Hospitals of Leicester NHS Trust. He gained his MBChB \& BMedSci degree at the University of Birmingham. He gained specialist training in pediatric allergy at St Mary Hospital, London and University Hospital Southampton Foundation Trust. He completed an Allergy MSc at Imperial College London and now regularly lectures on the food allergy module for the Allergy MSc at University of Southampton.

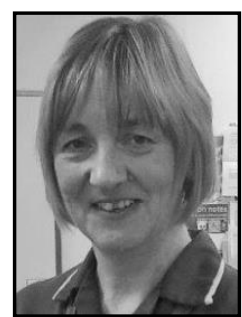

Kerrie Kirk is a Children's Allergy Specialist Nurse at Leicester Royal Infirmary. She has been qualified as a Registered Nurse since 1985 and as a Children's Nurse since 1988. She has worked in Birmingham Children's Hospital in infant cardiology and Leicester mostly on a respiratory ward followed by a medical Day Care ward prior to working with children with allergies which she has done for 12 years. She is a Specialist Nurse for children with allergies. She has been involved with research looking at the egg allergy and the flu vaccine in children for the last 2 years and is the Immunisation and Vaccination trainer for the Children's Hospital at University Hospitals of Leicester

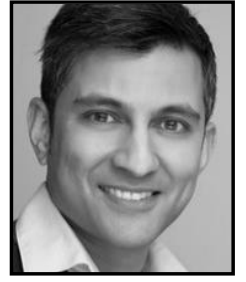

Nick Makwana graduated from the University of Birmingham Medical School and completed his pediatric training within the West Midlands. He has been a registrar at Birmingham Heartlands Hospital. He went on to work at Alder Hey Hospital in Liverpool and gained an MD from the Department of Clinical Infection, Microbiology and Immunology from the University of Liverpool. He is currently a consultant at Sandwell and West Birmingham NHS Trust (SWBH) and runs the pediatric allergy service cross site. He is one of the authors of the Management of Cows Milk Protein Allergy Guideline for BSACI and is the coordinator of the Midlands Pediatric Allergy Group. He trains doctors on the recognition and emergency management of children with life threatening conditions. He is an Honorary Clinical Lecturer in Pediatrics at the University of Birmingham and he is the Vice Chair on the examinations committee for the Royal College of Pediatrics and Child Health (RCPCH).

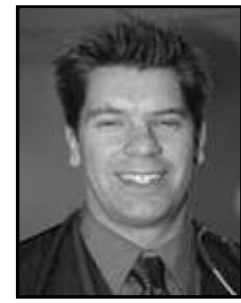

Tom C Dawson is a pediatrician with an interest in allergy based in Worcestershire. He completed his medical training at University College London and trained in pediatrics in the West Midlands. He has an MSc in Allergy from Imperial College and has previously been involved in vaccines research and surveillance studies into toxic shock syndrome and pollen food syndrome. He is currently studying pollen induced asthma with colleagues at the National Pollen Unit.

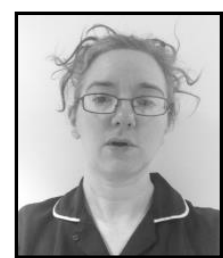

Cathryn Melchior is an Allergy Nurse Specialist at the Heart of England NHS Foundation Trust, which is one of the largest allergy centers in the UK, providing a comprehensive service for the diagnosis and management of all allergic conditions. Cathryn qualified in nursing in 2002 and worked in General Medicine and Critical Care before working in A\&E in major trauma centers in Nottingham and Birmingham. She joined the Heart of England allergy team in 2009 and has a particular interest in drug allergy.

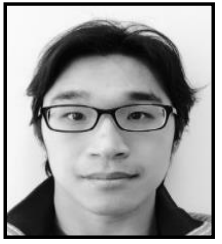

Gabriel Wong is a Wellcome Trust funded Clinical Research Fellow in Clinical Immunology at the University of Birmingham. He has substantial clinical experience in managing patients with allergic diseases and has published in the field of summation anaphylaxis and wheat-dependent exercise induced anaphylaxis.

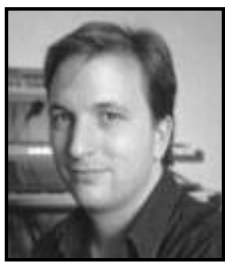

Tim Collins is an academic from the School of Electronic, Electrical and Systems Engineering at The University of Birmingham. His $\mathrm{PhD}$ was in the field of active sonar and he supervises research in applied signal processing for applications such as audio, digital heritage and medical devices.

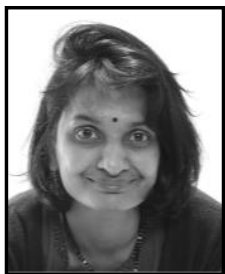

Lavanya Diwakar is a consultant immunologist employed at the University Hospital, Birmingham. She is currently undertaking a $\mathrm{PhD}$ in Health Economics at the University of Birmingham, where she is looking at ways to incorporate end user preferences into planning allergy services for the West Midlands and will estimate the costs and effectiveness of various possible pathways for delivery of these services. 